\title{
Hacia una nueva sistematización de las características del lenguaje dialógico/comunicativo
}

\section{Resumen}

Gabriel J. Zanotti

Facultad de Comunicación, Universidad Austral

Recibido: 19 de mayo de 2014. Aceptado: 2 de octubre de 2014.

Este trabajo trata sobre las condiciones del lenguaje dialógico y procura unificar las visiones de varios filósofos contemporáneos. Comienza por un análisis de las condiciones actitudinales del diálogo para luego pasar a sus juegos de lenguaje concomitantes. Concluye con la importancia cultural del tema en el mundo actual.

Palabras clave: comprensión, diálogo, hermenéutica, conciencia crítica, conciencia histórica, actos del habla.

\section{Towards a new systematization of the characteristics of dialogic/ communicative language}

\section{Summary}

This paper deals with the conditions of dialogic language and seeks to unify the views of several contemporary philosophers. It begins with an analysis of the attitudinal conditions of dialogue and then moves towards related language games. It concludes with the topic's cultural importance in the modern world.

Keywords: understanding, dialogue, hermeneutics, rational attitude, historical conscience, speech acts.

\section{Em direção a uma nova sistematização das características da lin- guagem dialógica/comunicativa}

\section{Resumo}

Esse trabalho trata sobre as condições da linguagem dialógica e procura unificar as visões de vários filósofos contemporâneos. Começa por uma análise das condições atitudinais do diálogo para logo apresentar seus jogos de linguagem concomitantes. Conclui fazendo referencia à importância cultural do tema no mundo atual.

Palavras chave: compreensão, diálogo, hermenêutica, consciência crítica, consciência histórica, atos da fala. 


\section{Introducción}

Cuando desde la hermenéutica se piensa a la comunicación como una fusión de horizontes (Gadamer, 1991) o como el proceso que conduce a un "eslabón participativo de sentido" entre ambos horizontes (Gadamer, 1998), lo que primero hay que aclarar es la posibilidad filosófica de esa comunicación. Gadamer afirma que sí, apelando a "lo humano" de todos los horizontes. Pero entonces la pregunta pasa a otro plano: suponiendo que es posible, ¿cuáles son las normas éticas para esa comunicación? Ese tema, excepto en Habermas (1987) se encuentra "disperso" en varios autores desde varias perspectivas filosóficas (Buber, Levinas, Gadamer, Popper) sin que sean integradas en una unidad coherente. Esa unidad es uno de los objetivos de este artículo.

Asumimos desde Habermas que esa comunicación —como diálogo, contrapuesta a manipulación - se refiere al lenguaje, pero no como palabra aislada, sino como proposición en su contexto pragmático (Wittgenstein, 1988; Conesa \& Nubiola, 1999) y en su sentido fenomenológico, esto es, la palabra como síntesis corpóreo-espiritual de "sentido" (Leocata, 2003). El diálogo en tanto lenguaje presupone actitudes morales ontológicamente previas, con respecto del otro (el "tú") que tienen una manifestación corporal, a través de la mirada, el rostro, las manos y toda la posición corporal, que implican por ende un lenguaje gestual, no verbal, que precede causalmente (por eso es "ontológicamente previo") a la palabra pronunciada. El eje central de este artículo está en las características del lenguaje dialógico como palabra pronunciada, sin ignorar que ello supone toda una actitud moral que se manifiesta en la totalidad del lenguaje corporal. Un breve repaso de esto no estará de más antes de comenzar con el lenguaje como palabra.

\section{La actitud moral del diálogo}

\subsection{El otro en tanto otro}

El diálogo es una actitud moral, contrapuesta a la manipulación del otro. Esa actitud se manifiesta en el respeto: respeto como la consideración del otro en tanto otro. Para dilucidar ese "en tanto otro" debemos recurrir a Buber (1994) con su clásica distinción yo-tú / yo-eso. Esto último es la relación persona-cosa - cosa, esto es, no persona- donde hay una legítima relación de manipulación e instrumentalización. A las cosas no-personas que son instrumentos de mi actuar cotidiano, en mi mundo de la vida (la tiza, el pizarrón, la computadora, el escritorio) 
las "manipulo" legítimamente, estableciendo una relación con ellas que es "eso para mí". Se usan y se reemplazan cuando ya no sirven para ese "para mí". En cambio, en el yo-tú, el tú se relaciona con el yo pero no es absorbido por el yo como cosa: mantiene su autonomía de persona y la relación para con él ya no es de eficacia (Habermas, 1987) sino de comprensión. La manera clásica de simbolizarlo es ésta:

a) Yo-eso (fig. 1)

b) Yo-tú (fig. 2)
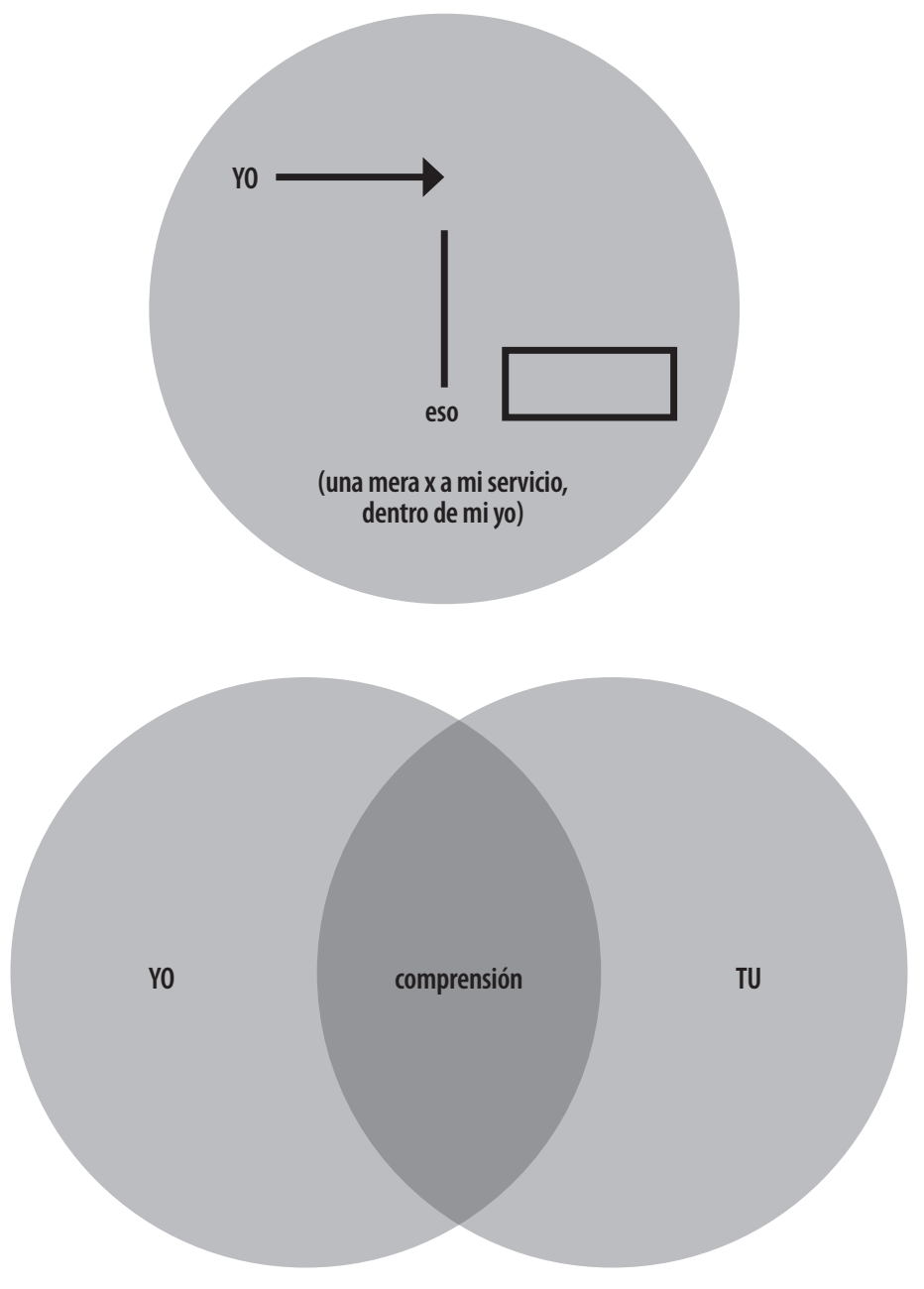


\subsection{Respeto y comprensión}

A su vez, cuando Habermas dice que la relación al otro ya no es por el éxito sino por la comprensión, está incorporando la noción de comprensión en Gadamer. Es decir que la relación yo-tú es ya una fusión de horizontes entre los horizontes de pre-comprensión personales (Gadamer, 1991), donde lo que se busca no es el dominio del otro sino el entendimiento del porqué del horizonte del otro y de su correspondiente "palabra" entendida como juego de lenguaje. Nosotros lo llamamos intersección de horizontes. La comprensión en ese caso implica una "defensa de" el otro en tanto se lo defiende del absurdo (Gadamer, 1998), del sin sentido aparente que tiene su mundo de la vida; implica que se ve cada afirmación del otro como la respuesta a una pregunta implícita en su horizonte (Gadamer, 1992). La comprensión busca entender. No busca dominar. El otro no es una cafetera con un manual de instrucciones.

\subsection{Comprensión y dignidad humana}

Pero ello implica, por lo tanto, que al respetar al otro en tanto otro se está respetando su dignidad como persona, esa dignidad que lo hace ser ontológicamente superior a cualquier animal no humano y que le da esa "inmunidad diplomática" ante cualquier intento de invasión a su territorio existencial.

Esa dignidad humana tiene tres fundamentos filosóficos posibles:

\section{a) Judeocristiana}

El ser humano tiene dignidad natural porque está hecho a imagen y semejanza de Dios. Así, tiene como características esencialmente humanas su inteligencia y su voluntad, por las cuales puede entender y decidir sus propios fines. Esta dignidad debe respetarse y ese deber es el origen del derecho a reclamar ese respeto, origen de sus derechos personales básicos. Esa dignidad no es moral, es ontológica; no se obtiene por méritos morales sino solo por ser persona y tampoco es la dignidad sobre-natural del bautismo, lo cual abre a una sociedad pluralista, con libertad religiosa y pleno respeto a los derechos todos (Ratzinger, 1987).

\section{b) Kantiana}

El modo anterior de fundamentar la dignidad de la persona no es pre-moderna, es moderna en el sentido de que fue defendida por escolásticos del siglo XVI (Fazio, 1998), por liberales católicos del siglo XIX (Serrano Redonet, 2012), por 
J. Maritain (1966) y por el Concilio Vaticano II en sus declaraciones Gaudium et spes y Dignitatis humanae (Vaticano II, 1981). Sin embargo, la noción de dignidad humana, si distinguimos con Leocata (2013) entre modernidad e iluminismo, es una noción iluminista que ha prevalecido en nuestros tiempos con Kant (1913) y un autor como J. Rawls es un claro ejemplo (1993). Según Kant la dignidad humana es la que corresponde a la autonomía de la voluntad entendida como el sujeto moral que es tal porque cumple con el deber por el deber mismo, pero además, por el segundo imperativo categórico según el cual no hay que tratar a nadie como medio sino como fin. Este es un modo kantiano de entender la relación de "respeto al otro" que tiene en Habermas su máximo exponente.

\section{c) Karol Wojtyla}

¿Son conciliables estos dos modos de entender la dignidad humana? A primera vista no, pero Karol Wojtyla sostiene - y nosotros adherimos- que el segundo imperativo categórico es esencialmente cristiano. Si el otro está creado a imagen y semejanza de Dios, es obvio que NO me pertenece y por ende no lo puedo invadir y ni cosificar y manipular, es decir, tratar como mero medio:

El origen de mis estudios centrados en el hombre, en la persona humana, es en primer lugar pastoral. Y es desde el ángulo de lo pastoral cómo, en Amor y responsabilidad, formulé el concepto de norma personalista. Tal norma es la tentativa de traducir el mandamiento del amoral lenguaje de la ética filosófica. La persona es un ser para el que la única dimensión adecuada es el amor. Somos justos en lo que afecta a una persona cuando la amamos: esto vale para Dios y vale para el hombre. El amor por una persona excluye que se la pueda tratar como un objeto de disfrute. Esta norma está ya presente en la ética kantiana y constituye el contenido del llamado segundo imperativo. No obstante, este imperativo tiene un carácter negativo y no agota todo el contenido del mandamiento del amor. Si Kant subraya con tanta fuerza que la persona no puede ser tratada como objeto de goce, lo hace para oponerse al utilitarismo anglosajón y, desde ese punto de vista, puede haber alcanzado su pretensión. Sin embargo, Kant no ha interpretado de modo completo el mandamiento del amor, que no se limita a excluir cualquier comportamiento que reduzca la persona a mero objeto de placer, sino que exige más: exige la afirmación de la persona en sí misma" (Wojtyla, 1994).

\subsection{El "privilegio ontológico" de la palabra}

Si todo esto es así, ¿por qué insistir entonces en el lenguaje dialógico "como palabra"? (Ya hemos aclarado que "palabra" es un modo alegórico de referirnos a los juegos del lenguaje). Porque la palabra $-\mathrm{y}$ esa es la diferencia con el lenguaje 
gestual - es, para el ser humano, su plenitud de sentido. Obsérvese que no hemos dicho "la" plenitud de sentido porque ello escapa a los límites de lo humano, por eso dijimos su plenitud de sentido. El lenguaje gestual acompaña a la palabra, pero si hacemos el intento de gesticular y no hablar, el otro siempre va a poder decir “¿pero qué quieres decir?”Y allí tendremos que pasar al lenguaje en su sentido de palabra. Por supuesto que el otro puede seguir repitiendo su pregunta, pero en ese caso puede ser que lleguemos a los límites del diálogo.

Recordemos que estamos hablando nada más ni nada menos que de "sentido". El famoso "lo que" alguien quiere decir en un contexto pragmático: alguien dice algo para algo y para alguien. Ese "algo" implica, como dice Leocata (2003), una perfecta reproducción del carácter corporal y espiritual del ser humano: corpóreo porque la palabra tiene un canal físico donde se expresa y queda grabada (garganta, cuerdas vocales, sonido, papiro, papel, silicio) pero a la vez manifiesta un sentido que no puede reducirse a ese canal físico y es universal (como el mundo 3 de Popper; Popper, 1998). Por eso el "hablar” es lo más “manifestativo” de lo humano.

\section{Características del lenguaje dialógico}

Llegamos entonces a nuestro eje central. Cuando este hablar manifiesta la relación yo-tú, ¿cuáles son sus características? $\mathrm{O}$, poniendo énfasis en el aspecto moral del diálogo: ¿cuáles son las normas del lenguaje dialógico para tratar al otro como otro?

\subsection{Los actos del habla}

El primer tema a tener en cuenta es el de los actos perlocutivos. Como es sabido, Habermas (1987) considera que los actos perlocutivos ocultos son estrategias orientadas al éxito y al consiguiente dominio del otro, lo cual implica que dichos actos del habla son impropios de la situación de diálogo y más bien característicos de los intentos de manipulación. Pero hay que distinguir entre los actos perlocutivos abiertos y ocultos. Los abiertos son "estrategias conocidas por el otro". Por ejemplo, si en un debate alguien dice "voy a tratar de convencerlos de..." y aclara que está abierto a la crítica, no hay manipulación; al contrario, hay diálogo. Por lo tanto, ese tipo de actos

\footnotetext{
Recordemos que en la primera y última versión de El planeta de los simios la palabra tiene un sentido especial en la trama, precisamente por lo que venimos diciendo. En la primera versión (http://www.imdb.com/title/ $\mathrm{tt} 0063442 /)$, el personaje protagonizado por $\mathrm{C}$. Heston tiene un grave problema precisamente porque no puede "hablar", hasta que finalmente lo hace y con ello re-voluciona toda la situación. En la última versión, El origen del planeta de los simios (http://www.imdb.com/title/tt1318514/) el "mono" (César) "dice" finalmente "no", ante lo cual un ser humano asombradísimo dice "habló".
} 
perlocutivos abiertos son dialógicos. Pero en esos casos son actos perlocutivos abiertos explícitamente. La mayoría de los abiertos son implícitos, dados por el marco cultural, es decir, son estrategias conocidas en un determinado momento de la vida. Los actos del habla utilizados en actos de compraventa (que incluye la publicidad), en formas de acercamiento entre los dos sexos, etc., son estrategias "presupuestas" que no necesariamente deben ser explicitadas al "outsider" (ver Schutz, 1970) y por ende no debe alguien sentirse manipulado por desconocer ese tipo de estrategias cuando desconoce un determinado mundo de la vida que las presupone.

Cabe aclarar que Habermas nunca consideraría "dialógicas" las estrategias comerciales en el mercado, pero en nuestro caso ya hemos dicho que mientras sean abiertas, sí lo son. Esto abre al tema del mercado y la comunicación, pero ello excede los objetivos de este artículo.

Por ende, podríamos establecer esta norma: el diálogo tiene como norma negativa la NO utilización de actos del habla perlocutivos ocultamente estratégicos.

Hay excepciones, si; por ejemplo un acto del habla de ese tipo que sea utilizado para "dominar" sanamente a un niño que se dirigía hacia un enchufe. Esta excepción también abre a otro tema político que nos excede: muchos dictadores utilizan este tipo de acciones del habla en sus discursos porque presuponen, precisamente, que sus destinatarios son niños, lo cual nos lleva a las causas psicológicas de la dominación (Fromm, 1957).

\subsection{El discurso "no coercitivo"}

R. Nozick (1981) afirma que el discurso filosófico debe ser "no coercitivo". ¿Qué significa ello? Que es perfectamente lícito argumentar a favor de la propia posición, pero siempre que se deje al otro "un espacio" (este tema se reiterará más adelante de otro modo) para pensar la conclusión a la cual se está llegando. Con ello se respeta el tiempo que cada persona tiene para llegar a sus propias conclusiones. Lo cual no sucedería si alguien precediera de este modo: "esta es la premisa mayor. ¿La ve? ¿Si? (e insiste hasta que el otro dice "si", nunca se sabe si para que el supuesto "maestro" deje de insistir). Bien, esta es la premisa menor, ¿la ve? (y el mismo proceso). Bueno, entonces, jesta es la conclusión!"

No. Un lenguaje dialógico deja siempre un espacio abierto para que el otro pueda pensar, meditar cada "premisa" de la conversación. No hay en este caso verbos performativos específicos, como en los actos del habla ilocutivos, sino juegos de lenguaje que manifiestan ese respeto a ese tiempo (por ejemplo: "mire, mi ar- 
gumentación parte de la siguiente premisa. Usted puede estar en desacuerdo, por supuesto, pero le propongo que la piense").

Ahora bien, esto no debe ser exclusivo para un discurso académico-filosófico. En toda conversación dialógica hay juegos de lenguaje que manifiestan ese "dejar pensar al otro", y por supuesto debe ser recíproco. Que no sea sencillo, es obvio, estamos hablando de un tema ético que implica generación de hábitos. Pero también una empatía y una sensibilidad especial precisamente por "lo otro del otro" que debemos estar siempre llamados a comprender desde una escucha misericordiosa (Pablo VI, 1964).

\subsection{Respetar el derecho a la interpelación del otro}

¿Qué es y cómo fundamentamos este "derecho a la interpelación"?

Dada la naturaleza intelectual del ser humano, la verdad solo puede verse por la sola fuerza de la verdad y no por la violencia, ya sea física o lingüística (si no se respetan los puntos 3.1. y 3.2). Por ende respetar la dignidad del otro significa el deber moral de no imponer la verdad por la fuerza. Luego todo ser humano tiene derecho a que la verdad no le sea impuesta por la fuerza, porque el derecho subjetivo del otro no es más que su derecho a reclamar nuestro deber.

Ese derecho se concreta en el derecho a la interpelación. Es decir, el derecho a la pregunta. Una pregunta que puede manifestar duda o desacuerdo momentáneo. En el respeto al derecho a la pregunta del otro se manifiesta concretamente que estamos respetando su derecho a que la verdad no le sea impuesta por la fuerza. Por supuesto eso implica respeto mutuo y ello hay que educarlo, pero aclaremos que ya estamos presuponiendo ese respeto que se manifieste en juegos de lenguaje cordiales para con el otro.

Surgen así tres consecuencias para toda conversación dialógica:

a) La pregunta no interrumpe, forma parte, al contrario, de la conversación. La escucha del discurso del otro no tiene que consistir en buscar la respuesta a partir de una serie de afirmaciones programadas (Gadamer, 1992) sino abrirse al nivel del discurso del otro. Es decir, no chocar como dos locomotoras "en curso de" colisión, sino precisamente cambiar el rumbo y ponerse "al lado de" el otro para no chocar. La pregunta implica entonces un ámbito de libertad que forma parte del orden del diálogo; no es por ello un des-orden del diálogo. Un des-orden sería un discurso que no admitiera preguntas, porque entonces sería un síntoma casi seguro de que se ha pasado del diálogo al intento de dominación del otro. 
b) El diálogo implica que los dialogantes se van escuchando mutuamente y haciendo las acotaciones necesarias por medio de los puntos 3.1. y 3.2. En ese sentido puede constituir un ejercicio mutuo de aprendizaje. En ese contexto no hay que "saber para preguntar" sino, al contrario, "preguntar para saber" porque el ejercicio mutuo de la pregunta y la respuesta es lo que lleva a la ampliación mutua de horizontes (Gadamer, 1992).

c) El que escucha la pregunta debe escucharla por la pregunta en sí misma. Toda pregunta es importante porque surge del otro. No es el contenido de la pregunta lo que la hace importante sino que manifiesta una preocupación auténtica del mundo interno del otro que se abre precisamente porque hay respeto. El que responde debe captar cuál es el horizonte del otro al hacer la pregunta, precisamente porque se halla en un contexto de comprensión. Por lo tanto, contrariamente a "todo lo que diga será usado en su contra", el diálogo implica que todos los dialogantes perciban que "todo lo que digan será usado a su favor".

\subsection{La distancia crítica}

El diálogo implica un hiato, una sana distancia que el otro se toma antes de asentir o disentir. Con el ejercicio del derecho a la interpelación, esa distancia crítica surge naturalmente. Es decir, el todos "están pensando" en el discurso del otro, sin tener que asentir o disentir de manera inmediata. Esa distancia no es un distanciamiento en el sentido de "enojo" sino todo lo contrario, es la libertad que surge en el respeto mutuo (fig. 3).

Esto implica tomar la noción de crítica de Popper (1983) y de Habermas (1987). En Popper la razón es igual a actitud crítica, estar abierto al diálogo. Por lo tanto, el ejercicio mismo de la razón implica abrirse a la crítica del otro y viceversa. Algunos han visto en esto un escepticismo panconjeturalista, como si la razón crítica fuera un resultado de la no-certeza de las hipótesis, pero Mariano Artigas (1998) ha demostrado - a nuestro juicio- que el diálogo es en Popper una actitud moral, que tiene certeza, donde la razón y la ética se igualan en una razón que "debe" estar abierta a recibir objeciones, llevando ello, por supuesto, al respeto al derecho a la interpelación del otro.

A su vez, Habermas (1987), después de sus tres condiciones de diálogo, habla de una cuarta que es criterio de validez de todas las demás. El discurso del otro puede ser, en cuanto a su aceptación, críticamente motivado o empíricamente motivado. 


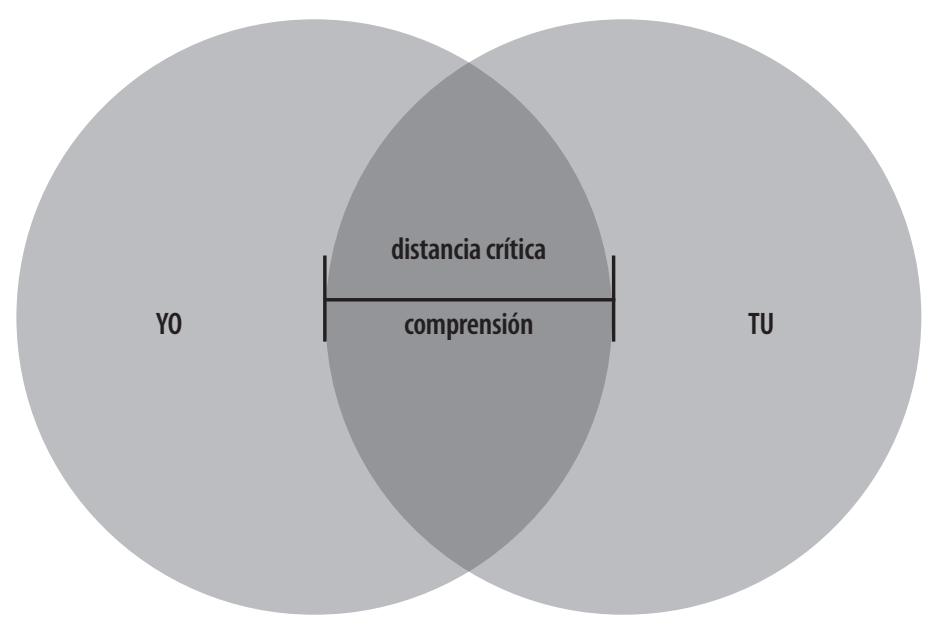

El primero deviene del ejercicio de la razón crítica al juzgar las condiciones de diálogo que el otro está respetando. Es casi similar a la distancia crítica. El segundo, en cambio, corta totalmente el diálogo y es la situación que se da en la dominación del otro: la "aceptación" del discurso del otro (decir que "si") deviene de algo externo al discurso, como ser los premios que se darán si digo que sí o los castigos que sufriré si digo que no. Si ello sucede, precisamente se han violado todas las reglas del lenguaje dialógico y estamos en plena situación de alienación del otro. La distancia crítica es la clave para que ello no suceda y, a su vez, respetar el derecho a la interpelación del otro es clave para que la distancia crítica se manifieste con sinceridad.

\subsection{La falsa dicotomía entre conciencia histórica y conciencia crítica}

Paul Ricoeur (2010) analizó el debate entre Habermas y Gadamer con respecto de estas dos "conciencias". La conciencia histórica en Gadamer (1993) implica tener una actitud teorética, filosófica, con respecto de los horizontes de pre-comprensión en los cuales estamos inmersos; es tener conciencia filosófica de ellos como condición de la comprensión de que el otro no habla desde el absurdo, sino desde su historicidad.

La conciencia crítica, en cambio, sería un discurso emancipatorio de las estructuras sociales opresoras que, por lo tanto, no conduciría solo a la comprensión del discurso imperante en determinada situación social, sino al cambio social y al cambio de estructuras. 
Independientemente del contenido neomarxista que Habermas da a la palabra "emancipación", vía la Escuela de Frankfurt, coincidimos en que la distancia crítica implica - aunque no siempre- la posibilidad de la crítica a las estructuras existentes (una crítica que no pasa, obviamente, por la dialéctica hegeliana como sinceramente pensaron Adorno y Horkheimer (1994). Pero ello no se opone a la conciencia histórica: la presupone. Esto es, la toma de conciencia filosófica de los presupuestos culturales de la propia época es una condición necesaria para que la crítica no devenga en el mero rechazo de lo que resulta absurdo, porque en ese caso la crítica es naiv, es decir, no comprende, no entiende, lo que critica. Luis J. Zanotti (1993) decía que la crítica es como el viento y la tradición es como la vela: el viento empuja al barco precisamente porque la vela le hace resistencia. Kuhn (1996) también explicó que los cambios de paradigma los pueden hacer solo los científicos que estaban formados teoréticamente en el paradigma anterior. Conciencia histórica y conciencia crítica van, en ese sentido, de la mano.

\section{Conclusión}

La filosofía del diálogo sigue teniendo una importancia crucial para nuestro tiempo. Por varios motivos:

a) Tiene implicaciones didácticas fundamentales. La interacción entre conciencia histórica y conciencia crítica es esencial para el proceso de aprendizaje que aún sigue estando concebido, muchas veces, bajo el modelo positivista de recepción pasiva de información.

b) Constituye uno de los ejes epistemológicos de la filosofía de la comunicación, entendida "comunicación" precisamente como la comprensión mutua de horizontes, contrariamente a la alienación. Es uno de los pilares, por ende, de una ética de la comunicación social.

c) En un mundo globalizado, donde, sin embargo permanecen las guerras, los muros culturales y las trabas legales a la libre circulación de personas, es necesario advertir que esa globalización no es compatible con una sola negociación que, a lo sumo, puede evitar una guerra dejándola latente. Los muros físicos y las guerras disminuyen a medida que aumenta la comprensión entre los pueblos. Esa comprensión puede ser fruto de una actitud teorética, donde el filósofo tiene mucho para seguir diciendo, o de una actitud natural donde la empatía para con el otro baje las trabas de la incomprensión. Esto también está abierto al comercio como comunicación, pero ello es tema de otro trabajo. 


\section{Referencias}

Adorno T.; Horkheimer, M. (1994). Dialéctica de la ilustración. Madrid: Trotta.

Artigas, M. (1998). Lógica y ética en Karl Popper. Pamplona: Ediciones de la Universidad de Navarra (EUNSA).

Buber, M. (1994). Yo y tú. Buenos Aires: Nueva Visión.

Conesa, F. \& Nubiola, J. (1999). Filosofía del lenguaje. Barcelona: Herder.

Fazio, M. (1998). Francisco de Vitoria, cristianismo y modernidad. Buenos Aires: Edit. Ciudad Argentina. Fromm, E. (1957). El miedo a la libertad. Buenos Aires: Paidós.

Gadamer, H.-G. (1991). Verdad y método I. Salamanca: Sígueme.

-. (1992). Verdad y método II. Salamanca: Sígueme.

-. (1993). El problema de la conciencia histórica. Madrid: Tecnos.

-. (1998). El giro hermenéutico. Madrid: Cátedra.

Habermas, J. (1987). Teoría de la acción comunicativa. Barcelona: Taurus.

Kant, I. (1913). Crítica de la razón práctica. Madrid: Librería de Victoriano Suárez.

Kuhn, T. S. (1996). La tensión esencial. México: Fondo de Cultura Económica.

Leocata, F. (2003). Persona, lenguaje, realidad. Buenos Aires: Editorial de la Universidad Católica Argentina (EDUCA).

-. (2013). La vertiente bifurcada. Buenos Aires: Editorial de la Universidad Católica Argentina (EDUCA).

Maritain, J. (1966). Humanismo integral. Buenos Aires: Carlos Lohlé.

Nozick, R. (1981). Philosophical explanations. Cambridge: Harvard University Press.

Pablo VI (1964). Ecclesiam suam. Buenos Aires: Ediciones Paulinas.

Popper, K. (1988). Conocimiento objetivo. Madrid: Tecnos.

-. (1983). Conjeturas y refutaciones. Barcelona: Paidós.

Ratzinger, J. (1987). Iglesia, ecumenismo y política. Madrid: Biblioteca de Autores Cristianos.

Rawls, J. (1993). Political liberalism. New York: Columbia University Press.

Ricoeur, P. (2010). Del texto a la acción: ensayos de hermenéutica II. México: Fondo de Cultura Económica.

Schutz, A. (1970). On phenomenology and social relations. Chicago: University of Chicago Press.

Serrano Redonet, D. (2012). El liberalismo católico en Francia en el siglo XIX y sus desafíos [artículo]. Grand Rapids, MI: Instituto Acton. Disponible en: http://es.acton.org/article/12/21/2012/elliberalismo-cat\%C3\%B3lico-en-francia-en-el-siglo-xix-y-sus-desaf\%C3\%ADos (consulta: oct. 2014).

Vaticano II (1981). Documentos conciliares. Buenos Aires: Ediciones Paulinas.

Wittgenstein, L. (1988). Investigaciones filosóficas. Barcelona: Crítica.

Wojtyla, K. (1994). Cruzando el umbral de la esperanza. Barcelona: Plaza y Janés.

Zanotti, Luis J. (1993). Su obra fundamental. Buenos Aires: Instituto de Investigaciones Educativas.

\section{Contacto}

\section{Gabriel J. Zanotti}

gabrielmises@yahoo.com 